\title{
Definição de segmentos homogêneos para o trecho da BR-040 que compreende a cidade de Congonhas/MG
}

As condições de trafegabilidade do pavimento de uma rodovia estão sujeitas às mais diversas variações ao longo de sua extensão; seja devido a características físicas; seja devido alterações no tráfego, no clima ou, em obras de revitalização. Dessa forma, muitos são os parâmetros considerados no desempenho do pavimento rodoviário, o que consequentemente, resultará em suas condições de trafegabilidade e, tornar-se-á, imprescindível, a consequente divisão da rodovia em segmentos homogêneos, os quais necessitam conter características estruturais e comportamentais semelhantes. Neste ínterim, este trabalho visa a elaborar uma nova proposta para segmentação homogênea da rodovia BR-040, trecho que compreende a cidade de Congonhas/MG, contribuindo assim com o processo de análise comportamental da rodovia. Para tanto, foram utilizadas informações do banco de dados da gerência de pavimentos da concessionária responsável pelo trecho entre Brasília/DF e Juiz de Fora/MG. A delimitação dos novos segmentos homogêneos foi determinada conforme o 'Método das Diferenças Acumuladas' (Analysis Unit Delineation by Cumulative Differences), recomendado pela American Association of State Highway and Tranportation Officials - AASHTO (1993) e definida com base na estrutura do pavimento, bem como parâmetros que refletem as condições estruturais e funcionais dos pavimentos. Foi possível a identificação de 45 segmentos homogêneos, evidenciando que houve alterações significativas nas condições estruturais e funcionais do pavimento analisado.

Palavras-chave: Pavimentos; Segmentos Homogêneos; Trafegabilidade.

\section{Defining homogeneous road sections for BR-040 inside minas' gerais city of Gongonhas perimeter}

\begin{abstract}
The highway pavement's traffic conditions are subject to several different variations along its length due its physical and intrinsical elements, changes in traffic conditions, climate or revitalization works. All of this considered, the parameters required to evaluate highway pavement performance are several, so it becomes crucial to split the highway into homogeneous segments, which must have similar structural and behavioral characteristics. In this context, this work targets to develop a new proposal for homogeneous segmentation for a section of the BR-040 - the section covering the city of Congonhas in Minas Gerais State - highway, in order to contribute to the behavioral analysis of the highway. In order to do it so, it was the used source of Pavement Management's database provided by the company responsible for the area between the Brasilia and Juiz Fora States. The delimitation of the new homogeneous segments was determined according to the "Accumulated Differences Method" (Analysis Unit Delineation by Cumulative Differences) recommended by American Association of State Highway and Tranportation Officials - AASHTO (1993)and defined on the basis of the pavement structure, as well as parameters that reflect the structural and functional conditions of the pavements. It was possible to identify 45 homogeneous segments, highlighting the significant changes in the structural and functional conditions of the pavement analyzed.
\end{abstract}

Keywords: Paviments; Homogeneous segments; Traffic conditions.

Topic: Sustentabilidade nos Transportes

Reviewed anonymously in the process of blind peer.

Camila Antunes Martins

Instituto Militar de Engenharia, Brasil

http://lattes.cnpq.br/8833923917344936

camilaantunes@ime.eb.br

Ben-Hur de Albuquerque e Silva (iD

Instituto Militar de Engenharia, Brasil

http://lattes.cnpq.br/6509325029666357

http://orcid.org/0000-0001-6933-498X

benhur@ime.eb.br

Maria Esther Soares Marques (iD

Instituto Militar de Engenharia, Brasil

http://lattes.cnpq.br/8911936841113704

http://orcid.org/0000-0001-8936-2777

esther@ime.ed.br

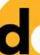

DOI: 10.6008/CBPC2179-6858.2018.005.0014
Received: 10/06/2018

Approved: 24/07/2018
Referencing this:

MARTINS, C. A.; SILVA, B.-H. A.; MARQUES, M. E. S.. Definição de segmentos homogêneos para o trecho da BR-040 que compreende a cidade de Congonhas/MG. Revista Ibero Americana de Ciências Ambientais, v.9, n.5, p.146-158, 2018. DOI: http://doi.org/10.6008/CBPC2179-6858.2018.005.0014 


\section{INTRODUÇÃO}

O transporte, em princípio, é uma atividade que afeta o desenvolvimento econômico e social dos países. Nesse ínterim, o crescimento da demanda por bens e serviços culmina com o desenvolvimento dos centros urbanos de maneira contundente; o que por sua vez, determina a expansão da produção das firmas e, também, do consumo da população geram necessidades de crescimento das atividades de indústrias e do comércio (MELLO, 1975; MARRA, 1999).

O sucesso e progresso da humanidade estão intrinsecamente ligados ao desenvolvimento e à qualidade da infraestrutura disponibilizados à sociedade (HUDSON et al., 1997). Segundo Lima (2004), para se obter um desenvolvimento mais compatível às particularidades de cada região, faz-se necessário o surgimento de modos de transportes eficientes e de qualidade. Dentre os fatores que mais condicionam a eficiência está a infraestrutura que os suporta.

Nessa perspectiva de Lima (2004), percebe-se que a melhor compreensão do comportamento dos pavimentos e o conhecimento das condições de estado atual de um pavimento são primordiais para a definição das soluções mais eficazes na aplicação dos recursos destinados às intervenções de reabilitação e manutenção em uma rodovia, visto que a falta de manutenção ou suspensão de sua utilização causam prejuízos econômicos críticos à população.

A rede rodoviária se constitui, assim, no âmbito dos meios de transportes existentes, a infraestrutura que melhor desempenha seu papel para o desenvolvimento pleno de qualquer país, pois além de permitir a cobertura completa do território nacional, o modo de transporte por vias rodoviárias se configura como o mais flexível, sendo o único capaz de realizar o transporte do tipo 'porta-a-porta' (MARTINS, 2017).

Quando se abre uma rodovia ao tráfego, o pavimento é submetido a solicitações que tendem a diminuir sua capacidade estrutural de resistir a cargas oriundas dos veículos que por ali trafegam, especialmente os de grande peso, e podem tornar a sua superfície irregular, elevando as chances de ocorrência de acidentes, o que diminui a velocidade dos veículos e estende o tempo de viagens, ou seja, gerando prejuízos - aumento de custos operacionais - a usuários e à administração da rodovia.

Além do investimento (inversão) inicial para a construção, os pavimentos continuam a despender um valor considerável de recursos financeiros ao longo do tempo. Em países como o Brasil, onde a malha rodoviária pavimentada é extensa - $213.591 \mathrm{~km}$, de acordo com a Confederação Nacional do Transporte CNT (2018) - estes gastos podem exigir grande esforço econômico do país, no sentido do valor adicionado da renda nacional, i.e., PIB (Produto Interno Bruto).

Dessa forma, a determinação da condição de superfície de um pavimento asfáltico, bem como a análise dos tipos e causas de efeitos, se configura como de suma importância para que sejam desenvolvidos projetos adequados à conservação ou ainda à recuperação das vias, tal que os recursos financeiros investidos em serviços de manutenção de pavimentos sejam alocados de forma criteriosa conseguintemente mais rentável (VIEIRA et al., 2016). 
A rodovia BR-040 desempenha papel importante no desenvolvimento econômico do país, interligando duas importantes regiões (Sudeste ao Centro Oeste): e também possui inúmeras empresas nacionais e estrangeiras instaladas próximas às adjacências, requerendo assim o desenvolvimento de uma metodologia de gestão dos dados relativos à pavimentação para compreender os mecanismos que governam o comportamento dos pavimentos e desenvolver técnicas e soluções que retornem resultados positivos à sociedade.

Neste contexto, o presente trabalho objetiva elaborar uma nova segmentação homogênea para determinado trecho da malha rodoviária da BR-040, situado na cidade de Congonhas/MG - próxima aos centros urbanos, onde o tráfego de veículos é bastante elevado - de forma a contribuir com o processo de análise comportamental da rodovia.

\section{REVISÃO TEÓRICA}

\section{Pavimentos Rodoviários}

Pavimento rodoviário é uma estrutura de múltiplas camadas de espessuras finitas, construída sobre a superfície final de terraplenagem, destinada, em tese, a resistir aos esforços oriundos do tráfego e cargas dos veículos, das condições climáticas possivelmente adversas, variações de temperatura dos materiais das camadas e ação da água - com viabilidade econômica, e a propiciar aos usuários melhoria nas condições de rolamento, com conforto, economia e segurança (BERNUCCI et al., 2008).

Todo pavimento é dimensionado para um determinado período de vida útil. Entretanto, ao final deste período, ou mesmo antes, devido às solicitações como o tráfego e condições climáticas, o pavimento poderá apresentar danos que comprometerão a sua estrutura e, também, sua capacidade de fornecer uma superfície de rolamento adequada para os usuários finais. Dessa maneira, evidencia-se que são necessárias intervenções que reparem ou retardem os efeitos destes danos, visando à manutenção das características adequadas de uma rodovia.

Os pavimentos rodoviários configuram-se como um valioso recurso da infraestrutura nacional de transportes terrestres, e medidas adequadas de conservação e restauração se tornam, assim, essenciais para assegurar sua preservação ao longo de sua vida útil. De acordo com Visconti (2000), quando o pavimento é restaurando no momento adequado, este poderá exigir apenas uma camada delgada de recapeamento sobreposta à estrutura atual, procedimento que é considerado de custo relativamente baixo.

Neste cenário, a Gerência de Pavimentos (GP) representa uma importante ferramenta de administração, a qual possibilita determinar de maneira eficaz a aplicação dos recursos disponíveis para manutenção da rodovia, satisfazendo às necessidades dos usuários e propiciando a melhor relação custo $x$ benefício (DNIT, 2011). No que se refere à determinação de alternativas de restauração, Bernucci et al. (2008, p. 463) destaca:

Para a definição de alternativas de restauração é necessário o estudo da condição do pavimento existente. Este estudo é precedido por uma avaliação funcional e uma avaliação estrutural. Essas avaliações fornecem dados para análise da condição da superfície do 
pavimento e de sua estrutura e também para a definição das alternativas de restauração apropriadas.

A condição da superfície do pavimento é verificada na avaliação funcional, por meio do levantamento da condição de irregularidade longitudinal, e análise de defeitos superficiais. Os principais defeitos considerados na avaliação funcional são: área trincada e severidade do trincamento, deformações permanentes e irregularidade longitudinal.

Já a condição da estrutura do pavimento de resistir às solicitações de carga nele aplicadas e de manter sua integridade estrutural, sem apresentar falhas significativas, é correspondente à avaliação estrutural, que acontece por meio de levantamentos não destrutivos pela determinação da deflexão superficial resultante da aplicação de uma carga conhecida. O principal parâmetro considerado na avaliação estrutural é a deflexão na superfície e a bacia de deformação. A deflexão geralmente é utilizada para delimitar segmentos considerados como homogêneos quanto à condição estrutural.

Bernucci et al. (2008) evidencia ainda que, por meio da análise dos resultados das avaliações é possível determinar soluções de restauração mais apropriadas para cada caso - que podem ser de cunho funcional ou de estrutura - e, em geral, para se fazer essa análise de alternativas de restauração, definemse segmentos homogêneos.

\section{Segmentação Homogênea}

As condições de trafegabilidade do pavimento de uma rodovia estão sujeitas a sofrerem diversas variações ao longo de sua extensão devido a características físicas, alterações no tráfego, clima ou obras de revitalização. Dessa forma, torna-se imprescindível a divisão da rodovia em segmentos homogêneos, os quais devem possuir características estruturais e comportamentais semelhantes.

Segundo Benevides (2006), dentre os procedimentos adotados para divisão da malha rodoviária, tem-se a divisão em segmentos homogêneos e a adoção de segmentos com extensão fixa, por exemplo, aproximadamente 200 metros. Entretanto, este último procedimento apresenta uma larga desvantagem em relação ao primeiro, visto que há grande possibilidade de haver diversidades nas características estruturais dos pavimentos.

Conforme recomenda DNIT (2006), em termos de homogeneidade, para a divisão dos segmentos devem ser considerados parâmetros pertinentes ao desempenho do pavimento existente e para a eficácia de medidas de restauração e/ou reabilitação, entre as quais: estaqueamento ou quilometragem, perfil de deflexões e raios de curvatura, flecha nas trilhas de roda, módulos elásticos, constituição do pavimento existente, defeitos ocorrentes, irregularidade longitudinal e tráfego solicitante. O referido manual informa que a definição dos segmentos homogêneos pode ser realizada em bases subjetivas; bem como recomenda que não haja parcelamento excessivo e nem segmentos superiores a $5 \mathrm{~km}$, devido a limitações construtivas.

Cabe salientar que o conceito de 'Segmentos Homogêneos' não deve ser confundido com o de 'Unidade de Amostragem', visto que o primeiro refere-se aos resultados de levantamentos detalhados de características de um determinado trecho da rodovia, onde se define a extensão de um trecho rodoviário 
contínuo com perfis semelhantes de desempenho (estrutura, tráfego, parâmetros de desempenho etc.), enquanto o segundo está relacionado com a escolha de um trecho da rodovia que caracteriza um tipo de pavimento de uma malha rodoviária (RODRIGUES, 2003).

Conforme recomenda a norma (DER-SP, 2006), a divisão em segmentos homogêneos do trecho avaliado pode ser realizada de acordo com duas metodologias: Pelo 'método das diferenças acumuladas' (Analysis Unit Delineation by Cumulative Differences), cujas aplicações, formulações e limitações são descritas no apêndice ' $\mathrm{J}$ ' do guia da American Association of State Highway and Tranportation Officials AASHTO (1993). Neste método qualquer parâmetro que defina a condição do pavimento quer seja ele funcional ou estrutural, pode ser empregado para a definição de segmentos com características semelhantes; Por meio de critério estatístico, conforme o procedimento do DNER (1979). Neste procedimento recomendase que para o segmento ser aceito o coeficiente de variação da amostra empregada, tenha valor de, no máximo, 0,30.

O procedimento indicado pela AASHTO (1993) é baseado no método das diferenças acumuladas, que, de acordo com Bernucci et. al., (2008) consiste na seguinte sequência de cálculo: Cálculo do valor médio da deflexão para todo o trecho ( $\sigma$ ); Cálculo da diferença entre cada valor individual e o valor médio; Cálculo dos valores acumulados das diferenças; Realização do gráfico, nas abscissas as distâncias e nas ordenadas os valores acumulados das diferenças. De um modo geral, os cálculos a se realizar seguem a seguinte expressão de cálculo:

$$
Z i=d i-d m+Z i-1
$$

Onde:

Zi = é a soma acumulada dos desvios da média ao ponto de ensaio; di = a deflexão máxima do ponto de ensaio i; $\mathrm{dm}=$ média da deflexão máxima para todo o trecho auscultado.

A Figura 1 ilustra um gráfico obtido pelo método descrito anteriormente. Como pode ser observada, cada variação de coeficiente angular da curva obtida, indica uma mudança do comportamento médio de um determinado segmento para outro, delimitando as extremidades dos segmentos homogêneos.

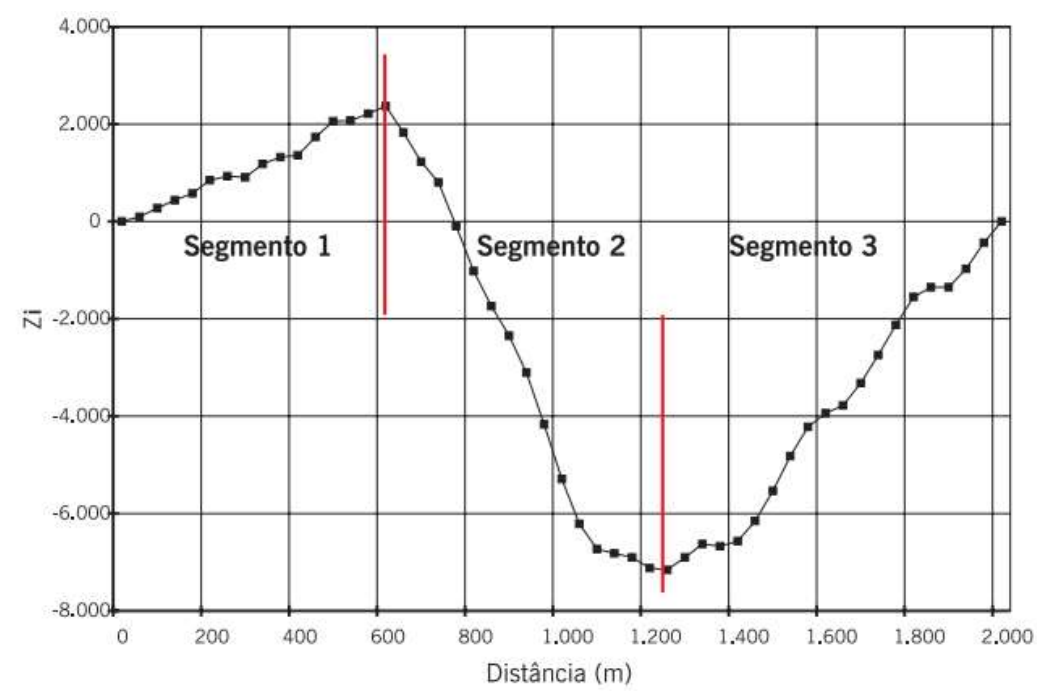

Figura 1: Exemplo de delimitação dos segmentos homogêneos pelo método das diferenças acumuladas. Fonte: AASHTO (1993, citado por BERNUCCl et al., 2008). 
Por meio da aplicação do 'Método das Diferenças Acumuladas' definido pela AASHTO (1993), a divisão dos trechos da rodovia em segmentos homogêneos pode ser realizada levando-se em consideração qualquer parâmetro que seja relevante. Porém, para avaliação estrutural de um pavimento, geralmente, é empregado o levantamento deflectométrico, uma vez que este pode caracterizar globalmente o pavimento.

\section{METODOLOGIA}

Foi selecionado um trecho da rodovia BR-040 que compreende a cidade mineira de Congonhas/MG, situada na região do quadrilátero ferrífero, entre o marco quilométrico $\mathrm{Km}$ 600+000 e Km 620+000, totalizando 20 quilômetros de extensão. Essa região é conhecida pela presença de grandes mineradoras ao longo das margens da rodovia, assim, o trecho apresenta um alto tráfego de veículos comerciais, especialmente aqueles carregados com minério de ferro.

Uma vez que podem ser encontradas características diferentes quanto à estrutura e condições do pavimento em um mesmo segmento homogêneo deflectométrico, levou-se em consideração a estrutura do pavimento e parâmetros que refletem as condições funcionais do mesmo. Para tanto, foram utilizadas informações, do ano de 2016, provenientes do banco de dados da gerência de pavimentos da concessionária responsável pelo trecho estudado.. As novas delimitações dos segmentos homogêneos contribuirão com parte do processo de tomada de decisão dos gestores na escolha de medidas eficazes de manutenção da rodovia, de forma a garantir o melhor estado de conservação dentro dos parâmetros de controle existentes do pavimento ao longo de sua vida útil - tanto a nível de políticas públicas quanto na tomada de decisão para a estratégia empresarial, o lado do setor privado da economia.

Sendo assim, a nova segmentação homogênea foi definida então, por meio do 'Método das Diferenças Acumuladas' a parir de uma hierarquização, considerando, em ordem Geomorfologia - trecho situado dentro das limitações do quadrilátero ferrífero -, deflexão (Do), defeitos de superfície, trincamento, afundamento em trilhas de roda (ATR), irregularidade longitudinal - medida na escala Internacional Roughness Index (IRI) - e espessura da camada de revestimento medida por Ground Penetrating Radar (GPR). Por conseguinte, foram calculados os valores médios que os representam.

A medição da deflexão foi realizada com o equipamento Falling Weight Deflectometer (FWD), que se caracteriza por ser um equipamento dispendioso, entretanto possibilita medições mais rápidas em relação ao levantamento com a Viga Benkelman. Foi fixada a extensão mínima para o novo segmento homogêneo em 300 metros, devido às limitações de ordem construtiva.

\section{RESULTADOS E DISCUSSÃO}

\section{Segmentação homogênea em função da deflexão ( $\left.D_{\circ}\right)$}

A segmentação homogênea definida conforme os valores de deflexão máxima (Do) - obtida por meio do equipamento FWD - resultou na identificação de 37 segmentos distintos. A extensão desses segmentos ficou definida entre 200 e 3.000 metros. O Gráfico 1 apresenta as diferenças acumuladas, onde cada ponto 
de inflexão do gráfico limita os segmentos homogêneos com características similares, todavia, devido à grande quantidade de segmentos identificados em uma curta extensão do trecho, não foi possível indicação no gráfico da divisão dos segmentos. Logo, pode-se verificar que há grande variabilidade da condição estrutural do pavimento ao longo do trecho analisado.

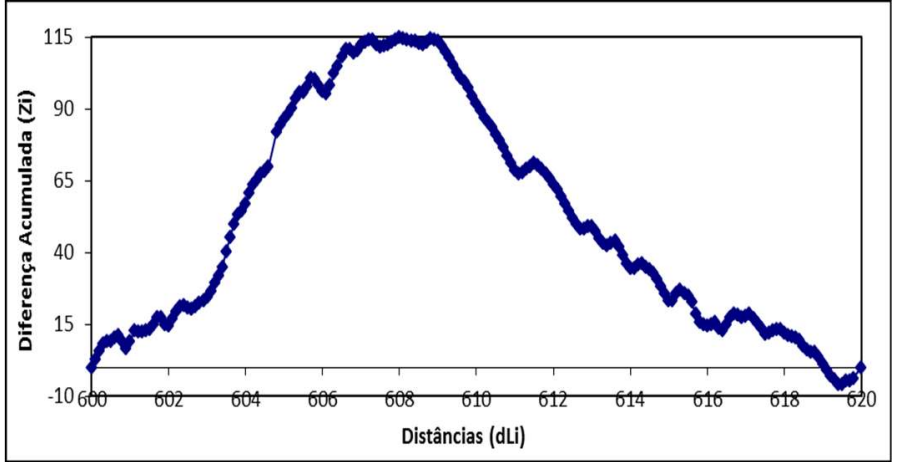

Gráfico 1: Divisão de segmentos homogêneos em função da deflexão (Do).

\section{Segmentação homogênea em função do percentual de área trincada}

A divisão do trecho analisado em função do percentual de área trincada, como pode ser observado no Gráfico 2, resultou na identificação de 4 segmentos homogêneos. A extensão dos segmentos ficou entre 1.000 e 9.000 metros, logo, o segmento de maior extensão ultrapassou o limite recomendado pelo DNIT (2006) e, sendo assim, observa-se que as condições superficiais do pavimento, no que diz respeito à trincamento, encontram-se similares na grande parte do trecho estudado.

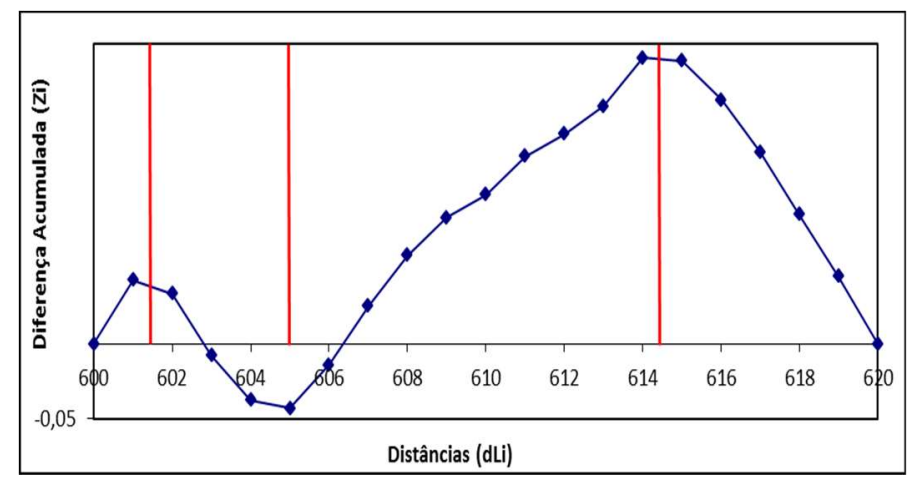

Gráfico 2: Divisão de segmentos homogêneos em função da área trincada.

\section{Segmentação homogênea em função do afundamento de trilha de roda (ATR)}

A segmentação homogênea definida conforme o parâmetro funcional afundamento trilha de roda resultou na identificação de 41 segmentos distintos. A extensão desses segmentos ficou definida entre 100 e 1.400 metros. Dessa maneira, evidencia-se que houve o parcelamento excessivo. O Gráfico 3 apresenta as diferenças acumuladas, porém assim como no gráfico 1, devido à grande quantidade de segmentos identificados em uma curta extensão do trecho, não foi possível indicação no gráfico da divisão dos segmentos, o que evidencia a variabilidade da condição funcional do pavimento analisado. 


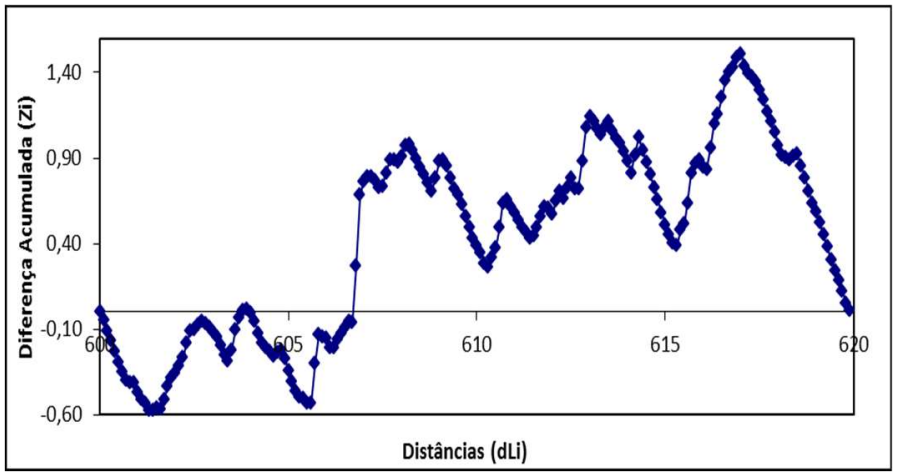

Gráfico 3: Divisão de segmentos homogêneos em função do afundamento de trilha de roda.

\section{Segmentação homogênea em função da irregularidade longitudinal (IRI)}

A divisão dos trechos homogêneos segundo o parâmetro de irregularidade longitudinal resultou na determinação de 16 segmentos distintos entre si. As limitações dos segmentos homogêneos podem ser observadas no Gráfico 4. Esta divisão apresentou segmentos de no mínimo 200 metros de extensão e máximo de 4.800 metros. Ainda conforme Gráfico 4, pode-se destacar que boa parte da variabilidade dos valores de IRI concentram-se em curtos intervalos do trecho.

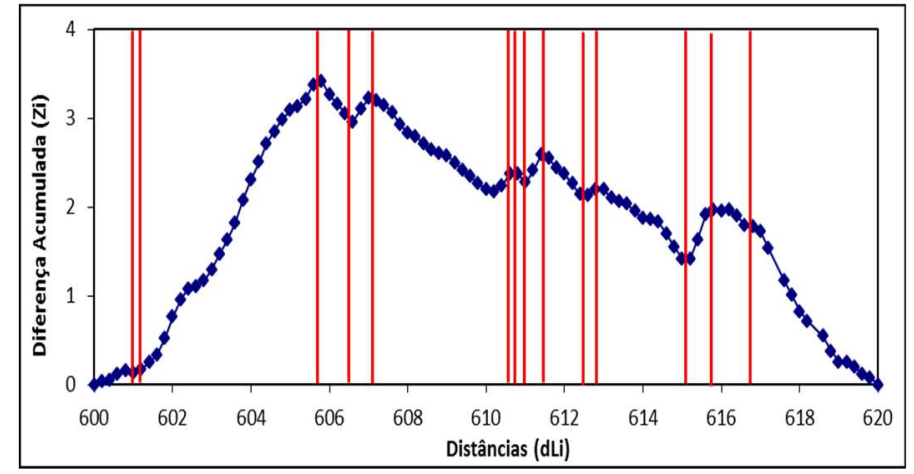

Gráfico 4: Divisão de segmentos homogêneos em função da irregularidade longitudinal.

\section{Segmentação homogênea em função da espessura do concreto asfáltico (CA)}

A divisão do trecho analisado em função da espessura do concreto asfáltico (CA), como pode ser observado no Gráfico 5, resultou na identificação de 4 segmentos homogêneos. A extensão dos segmentos ficou entre 400 e 13.700 metros, logo, o segmento 1, cujo apresentou maior extensão, ultrapassou o limite recomendado pelo DNIT (2006). Todavia, é possível observar que 70\% do trecho apresenta espessura do concreto asfáltico constante, havendo ainda, poucas alterações.

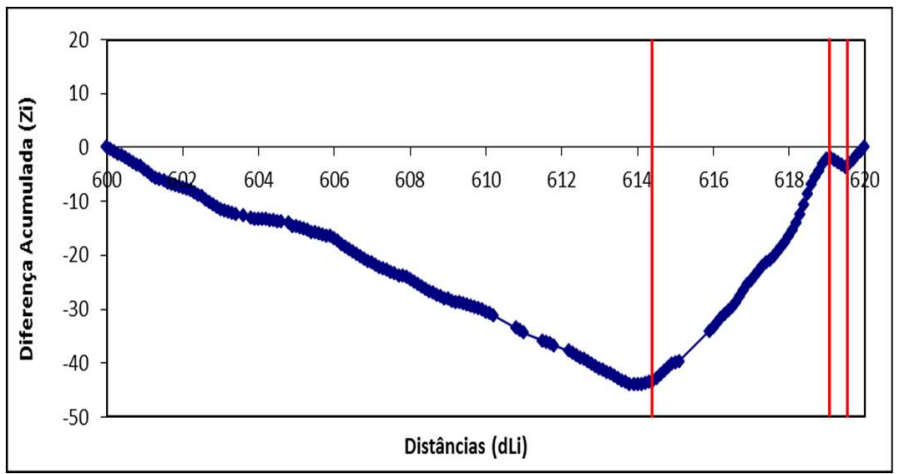

Gráfico 5: Divisão de segmentos homogêneos em função da espessura do concreto asfáltico 


\section{Segmentação Homogênea em Matriz Única}

Uma vez determinados os segmentos homogêneos no que diz respeito à deflexão, trincamento, afundamento de trilha de roda, irregularidade longitudinal e espessura do concreto asfáltico após aplicação do método das diferenças acumuladas recomendado pela AASHTO (1993), foi realizada a fusão - ou interpolação - em matriz única destes segmentos. Na Tabela 1 são apresentadas as quantidades de segmentos homogêneos obtidos para cada parâmetro avaliado.

Tabela 1: Segmentos por parâmetro obtidos por meio do Método das Diferenças Acumuladas.

\begin{tabular}{|l|l|l|l|l|}
\hline$D_{0}$ & TR & ATR & IRI & CA \\
\hline 37 & 04 & 41 & 16 & 04 \\
\hline
\end{tabular}

Devido ao critério de hierarquia adotado, foi possível a identificação de 45 segmentos homogêneos ao longo do trecho analisado. Percebe-se que houve aumento significativo em relação à divisão anterior estabelecida pela empresa responsável pela concessão do trecho da rodovia, visto que o trecho analisado era divido em apenas 13 segmentos com características semelhantes. Tal acréscimo na quantidade de segmentos homogêneos identificados pode ser explicado em função de alterações no tráfego, assim como obras de revitalização realizadas desde a última delimitação dos segmentos.

Como já mencionado, o trecho está situado dentro das limitações da cidade de Congonhas/MG, a qual faz parte das cidades que compõe o quadrilátero ferrífero. Congonhas tornou-se atualmente um polo urbano com alto volume de tráfego, sendo observado como trecho crucial para deslocamentos e impactante para o desenvolvimento da região. Dessa forma, é possível que tal trecho tenha sofrido alterações em suas condições funcionais e componentes estruturais devido à mudança na tolerância de sobrecarga nos eixos dos veículos segundo a Lei 13.103 (Brasil, 2015) a qual autoriza o acréscimo da sobrecarga nos eixos dos caminhões por $10 \%$.

Outro fato que evidencia alterações de rolagem e possíveis alterações estruturais são as obras de revitalização realizadas na rodovia. A concessionária responsável pelo trecho disponibilizou o histórico de intervenções realizadas no período entre 2015 e 2016 - intervalo entre a realização das duas divisões dos segmentos homogêneos. Entre o marco quilométrico Km 600+000 e Km 620+000 constatou-se a realização de 95 intervenções de revitalização, na qual foram empregados como solução a fresagem do revestimento asfáltico e recomposição com concreto asfáltico. Definida a nova segmentação homogênea, fez-se a relação dos segmentos homogêneos indicando os valores médios dos parâmetros utilizados para elaboração dos estudos de segmentação, conforme apresentado na Tabela 2.

Tabela 2: Segmentos homogêneos e seus respectivos valores médios dos parâmetros utilizados para elaboração dos estudos de segmentação.

\begin{tabular}{|l|l|l|l|l|l|l|l|l|}
\hline SH & Km inicial & Km final & Extensão & Do & Trincas & ATR Médio & IRI Médio & CA \\
\hline 01 & 600,00 & 600,70 & 700 & 59,90 & $10,29 \%$ & 0,18 & 3,01 & 6,6 \\
\hline 02 & 600,70 & 601,00 & 300 & 40,83 & $10,29 \%$ & 0,54 & 2,58 & 6,7 \\
\hline 03 & 601,00 & 601,30 & 300 & 58,40 & $7,20 \%$ & 0,33 & 2,95 & 5,2 \\
\hline 04 & 601,30 & 601,60 & 300 & 47,23 & $7,20 \%$ & 0,66 & 3,18 & 7,3 \\
\hline 05 & 601,60 & 602,00 & 400 & 47,30 & $7,20 \%$ & 1,25 & 3,73 & 8,0 \\
\hline 06 & 602,00 & 602,40 & 400 & 62,13 & $0,00 \%$ & 1,36 & 3,70 & 7,3 \\
\hline 07 & 602,40 & 602,70 & 300 & 38,57 & $0,00 \%$ & 0,96 & 2,89 & 6,2 \\
\hline
\end{tabular}




\begin{tabular}{|c|c|c|c|c|c|c|c|c|}
\hline 08 & 602,70 & 603,40 & 700 & 58,79 & $0,69 \%$ & 0,39 & 3,51 & 7,1 \\
\hline 09 & 603,40 & 603,90 & 500 & 82,44 & $0,69 \%$ & 1,34 & 3,85 & 8,8 \\
\hline 10 & 603,90 & 604,60 & 700 & 63,13 & $2,40 \%$ & 0,34 & 3,73 & 9,7 \\
\hline 11 & 604,60 & 605,00 & 400 & 80,78 & $2,40 \%$ & 0,58 & 3,44 & 10,7 \\
\hline 12 & 605,00 & 605,50 & 500 & 62,98 & $5,49 \%$ & 0,32 & 3,06 & 8,2 \\
\hline 13 & 605,50 & 605,80 & 300 & 61,50 & $5,49 \%$ & 2,12 & 3,97 & 9,3 \\
\hline 14 & 605,80 & 606,20 & 400 & 26,23 & $9,26 \%$ & 0,37 & 1,98 & 7,0 \\
\hline 15 & 606,20 & 606,60 & 400 & 76,93 & $9,26 \%$ & 1,15 & 2,21 & 5,7 \\
\hline 16 & 606,60 & 607,00 & 400 & 44,65 & $9,26 \%$ & 2,76 & 3,46 & 6,6 \\
\hline 17 & 607,00 & 607,40 & 400 & 45,33 & $7,54 \%$ & 0,74 & 2,63 & 6,9 \\
\hline 18 & 607,40 & 607,80 & 400 & 39,20 & $7,54 \%$ & 1,11 & 2,36 & 7,6 \\
\hline 19 & 607,80 & 608,20 & 400 & 45,30 & $8,23 \%$ & 0,98 & 2,25 & 7,4 \\
\hline 20 & 608,20 & 608,60 & 400 & 36,15 & $8,23 \%$ & 0,28 & 2,37 & 6,1 \\
\hline 21 & 608,60 & 609,10 & 500 & 42,28 & $5,83 \%$ & 0,86 & 2,57 & 7,8 \\
\hline 22 & 609,10 & 610,20 & 1100 & 18,75 & $6,17 \%$ & 0,20 & 2,38 & 8,1 \\
\hline 23 & 610,20 & 610,80 & 600 & 18,88 & $6,17 \%$ & 1,32 & 3,22 & 5,8 \\
\hline 24 & 610,80 & 611,10 & 300 & 16,87 & $7,89 \%$ & 0,41 & 2,25 & 6,6 \\
\hline 25 & 611,10 & 611,40 & 300 & 47,73 & $7,89 \%$ & 0,32 & 4,36 & 6,2 \\
\hline 26 & 611,40 & 611,80 & 400 & 38,03 & $7,89 \%$ & 1,08 & 2,55 & 7,9 \\
\hline 27 & 611,80 & 612,20 & 400 & 21,85 & $4,11 \%$ & 1,08 & 2,43 & 8,2 \\
\hline 28 & 612,20 & 612,50 & 300 & 16,00 & $4,11 \%$ & 1,00 & 2,16 & 7,0 \\
\hline 29 & 612,50 & 612,80 & 300 & 22,90 & $4,11 \%$ & 0,56 & 2,93 & 6,2 \\
\hline 30 & 612,80 & 613,30 & 500 & 33,32 & $4,11 \%$ & 1,34 & 2,63 & 6,9 \\
\hline 31 & 613,30 & 613,60 & 300 & 42,87 & $8,57 \%$ & 0,82 & 2,72 & 6,5 \\
\hline 32 & 613,60 & 614,00 & 400 & 17,38 & $8,57 \%$ & 0,29 & 2,36 & 8,2 \\
\hline 33 & 614,00 & 614,30 & 300 & 46,60 & $8,57 \%$ & 1,20 & 2,70 & 11,4 \\
\hline 34 & 614,30 & 615,10 & 800 & 23,28 & $1,71 \%$ & 0,00 & 2,11 & 15,5 \\
\hline 35 & 615,10 & 615,80 & 700 & 45,03 & $1,71 \%$ & 1,24 & 3,88 & 7,2 \\
\hline 36 & 615,80 & 616,10 & 300 & 32,37 & $1,71 \%$ & 0,65 & 2,71 & 17,7 \\
\hline 37 & 616,10 & 616,40 & 300 & 46,47 & $2,06 \%$ & 1,83 & 2,40 & 18,4 \\
\hline 38 & 616,40 & 616,70 & 300 & 62,80 & $2,06 \%$ & 1,51 & 2,27 & 18,1 \\
\hline 39 & 616,70 & 617,10 & 400 & 41,25 & $2,06 \%$ & 0,97 & 2,48 & 20,8 \\
\hline 40 & 617,10 & 617,50 & 400 & 42,18 & $0,00 \%$ & 0,35 & 1,77 & 18,5 \\
\hline 41 & 617,50 & 617,80 & 300 & 45,73 & $0,00 \%$ & 0,11 & 1,97 & 17,7 \\
\hline 42 & 617,80 & 618,50 & 700 & 35,23 & $0,00 \%$ & 0,47 & 2,13 & 23,9 \\
\hline 43 & 618,50 & 619,10 & 600 & 34,47 & $0,00 \%$ & 0,07 & 2,06 & 23,5 \\
\hline 44 & 619,10 & 619,50 & 400 & 22,40 & $0,00 \%$ & 0,00 & 2,52 & 10,5 \\
\hline 45 & 619,50 & 620,00 & 500 & 52,36 & $0,00 \%$ & 0,20 & 2,55 & 17,4 \\
\hline
\end{tabular}

Após a determinação da segmentação homogênea foram estabelecidas classes para os parâmetros que refletem os mecanismos de deterioração dos pavimentos em conformidade com o recomendado pelos manuais do HDM-4 (Highway Development and Management) - Software empregado para gerência de pavimentos - e DNIT (2011). No que se refere à suficiência estrutural, no HDM-4 esta é definida pelo Número Estrutural Corrigido (SNC), sendo assim, para avaliar os seguimentos homogêneos definidos neste trabalho, o SNC foi transformado em valor de deflexão $(0,01 \mathrm{~mm})$. A seguir é apresentado o resultado da avaliação das médias da nova segmentação homogênea para cada parâmetro, com pode ser observado na Tabela 3.

Tabela 3: Classificação das médias obtidas para cada segmento homogêneo no que se refere à deflexão, trincamento, afundamento de trilha de roda, irregularidade longitudinal e espessura do concreto asfáltico.

\begin{tabular}{|l|l|l|l|l|l|l|l|l|l|l|}
\hline S & Do & Classificaçã & Trinca & Classificaçã & ATR & Classificaçã & IRI & Classificaçã & CA & Classificaçã \\
\hline 01 & 59,9 & Bom & 10,29 & Regular & 0,18 & Ótimo & 3,01 & Regular & 6,6 & Bom \\
\hline 02 & 40,8 & Ótimo & 10,29 & Regular & 0,54 & Ótimo & 2,58 & Bom & 6,7 & Bom \\
\hline 03 & 58,4 & Bom & $7,20 \%$ & Regular & 0,33 & Ótimo & 2,95 & Bom & 5,2 & Bom \\
\hline 04 & 47,2 & Ótimo & $7,20 \%$ & Regular & 0,66 & Ótimo & 3,18 & Regular & 7,3 & Bom \\
\hline 05 & 47,3 & Ótimo & $7,20 \%$ & Regular & 1,25 & Ótimo & 3,73 & Regular & 8,0 & Bom \\
\hline 06 & 62,1 & Bom & $0,00 \%$ & Ótimo & 1,36 & Ótimo & 3,70 & Regular & 7,3 & Bom \\
\hline 07 & 38,5 & Ótimo & $0,00 \%$ & Ótimo & 0,96 & Ótimo & 2,89 & Bom & 6,2 & Bom \\
\hline 08 & 58,7 & Bom & $0,69 \%$ & Bom & 0,39 & Ótimo & 3,51 & Regular & 7,1 & Bom \\
\hline 09 & 82,4 & Regular & $0,69 \%$ & Bom & 1,34 & Ótimo & 3,85 & Regular & 8,8 & Bom \\
\hline
\end{tabular}




\begin{tabular}{|c|c|c|c|c|c|c|c|c|c|c|}
\hline 10 & 63,1 & Bom & $2,40 \%$ & Bom & 0,34 & Ótimo & 3,73 & Regular & 9,7 & Bom \\
\hline 11 & 80,7 & Regular & $2,40 \%$ & Bom & 0,58 & Ótimo & 3,44 & Regular & 10, & Regular \\
\hline 12 & 62,9 & Bom & $5,49 \%$ & Regular & 0,32 & Ótimo & 3,06 & Regular & 8,2 & Bom \\
\hline 13 & 61,5 & Bom & $5,49 \%$ & Regular & 2,12 & Bom & 3,97 & Regular & 9,3 & Bom \\
\hline 14 & 26,2 & Ótimo & $9,26 \%$ & Regular & 0,37 & Ótimo & 1,98 & Bom & 7,0 & Bom \\
\hline 15 & 76,9 & Regular & $9,26 \%$ & Regular & 1,15 & Ótimo & 2,21 & Bom & 5,7 & Bom \\
\hline 16 & 44,6 & Ótimo & $9,26 \%$ & Regular & 2,76 & Bom & 3,46 & Regular & 6,6 & Bom \\
\hline 17 & 45,3 & Ótimo & $7,54 \%$ & Regular & 0,74 & Ótimo & 2,63 & Bom & 6,9 & Bom \\
\hline 18 & 39,2 & Ótimo & $7,54 \%$ & Regular & 1,11 & Ótimo & 2,36 & Bom & 7,6 & Bom \\
\hline 19 & 45,3 & Ótimo & $8,23 \%$ & Regular & 0,98 & Ótimo & 2,25 & Bom & 7,4 & Bom \\
\hline 20 & 36,1 & Ótimo & $8,23 \%$ & Regular & 0,28 & Ótimo & 2,37 & Bom & 6,1 & Bom \\
\hline 21 & 42,2 & Ótimo & $5,83 \%$ & Regular & 0,86 & Ótimo & 2,57 & Bom & 7,8 & Bom \\
\hline 22 & 18,7 & Ótimo & $6,17 \%$ & Regular & 0,20 & Ótimo & 2,38 & Bom & 8,1 & Bom \\
\hline 23 & 18,8 & Ótimo & $6,17 \%$ & Regular & 1,32 & Ótimo & 3,22 & Regular & 5,8 & Bom \\
\hline 24 & 16,8 & Ótimo & $7,89 \%$ & Regular & 0,41 & Ótimo & 2,25 & Bom & 6,6 & Bom \\
\hline 25 & 47,7 & Ótimo & $7,89 \%$ & Regular & 0,32 & Ótimo & 4,36 & Ruim & 6,2 & Bom \\
\hline 26 & 38,0 & Ótimo & $7,89 \%$ & Regular & 1,08 & Ótimo & 2,55 & Bom & 7,9 & Bom \\
\hline 27 & 21,8 & Ótimo & $4,11 \%$ & Bom & 1,08 & Ótimo & 2,43 & Bom & 8,2 & Bom \\
\hline 28 & 16,0 & Ótimo & $4,11 \%$ & Bom & 1,00 & Ótimo & 2,16 & Bom & 7,0 & Bom \\
\hline 29 & 22,9 & Ótimo & $4,11 \%$ & Bom & 0,56 & Ótimo & 2,93 & Bom & 6,2 & Bom \\
\hline 30 & 33,3 & Ótimo & $4,11 \%$ & Bom & 1,34 & Ótimo & 2,63 & Bom & 6,9 & Bom \\
\hline 31 & 42,8 & Ótimo & $8,57 \%$ & Regular & 0,82 & Ótimo & 2,72 & Bom & 6,5 & Bom \\
\hline 32 & 17,3 & Ótimo & $8,57 \%$ & Regular & 0,29 & Ótimo & 2,36 & Bom & 8,2 & Bom \\
\hline 33 & 46,6 & Ótimo & $8,57 \%$ & Regular & 1,20 & Ótimo & 2,70 & Bom & 11, & Regular \\
\hline 34 & 23,2 & Ótimo & $1,71 \%$ & Bom & 0,00 & Ótimo & 2,11 & Bom & 15, & Ruim \\
\hline 35 & 45,0 & Ótimo & $1,71 \%$ & Bom & 1,24 & Ótimo & 3,88 & Regular & 7,2 & Bom \\
\hline 36 & 32,4 & Ótimo & $1,71 \%$ & Bom & 0,65 & Ótimo & 2,71 & Bom & 17, & Ruim \\
\hline 37 & 46,4 & Ótimo & $2,06 \%$ & Bom & 1,83 & Ótimo & 2,40 & Bom & 18, & Ruim \\
\hline 38 & 62,8 & Bom & $2,06 \%$ & Bom & 1,51 & Ótimo & 2,27 & Bom & 18, & Ruim \\
\hline 39 & 41,2 & Ótimo & $2,06 \%$ & Bom & 0,97 & Ótimo & 2,48 & Bom & 20, & Péssimo \\
\hline 40 & 42,1 & Ótimo & $0,00 \%$ & Ótimo & 0,35 & Ótimo & 1,77 & Bom & 18, & Ruim \\
\hline 41 & 45,7 & Ótimo & $0,00 \%$ & Ótimo & 0,11 & Ótimo & 1,97 & Bom & 17 & Ruim \\
\hline 42 & 35,2 & Ótimo & $0,00 \%$ & Ótimo & 0,47 & Ótimo & 2,13 & Bom & 23 & Péssimo \\
\hline 43 & 34,4 & Ótimo & $0,00 \%$ & Ótimo & 0,07 & Ótimo & 2,06 & Bom & 23, & Péssimo \\
\hline 44 & 22,4 & Ótimo & $0,00 \%$ & Ótimo & 0,00 & Ótimo & 2,52 & Bom & 10, & Regular \\
\hline 45 & 52,3 & Bom & $0,00 \%$ & Ótimo & 0,20 & Ótimo & 2,55 & Bom & 17, & Ruim \\
\hline
\end{tabular}

Os segmentos homogêneos apresentaram condições satisfatórias em relação à deflexão, trincamento e afundamento de trilha de roda, variando sua condição entre 'ótima' e 'regular'. O parâmetro irregularidade longitudinal também demonstrou boas condições, porém apenas o seguimento homogêneo no 25 apresentou condição 'ruim'. Já no que diz respeito a espessura do concreto asfáltico, de 45 segmentos homogêneos, 10 apresentaram condições entre 'ruim' e 'péssimo'. No âmbito geral, percebe-se que o trecho da rodovia analisada apresenta boas condições estruturais e funcionais, conforme especificações do HDM-4 e DNIT (2011).

\section{CONCLUSÕES}

Ao longo da vida útil de uma rodovia, alguns aspectos como mudanças climáticas de uma região e aumento do tráfego de veículos pesados, podem alterar significativamente as condições previstas em projeto e, por conseguinte, ditar o sucesso ou insucesso de uma solução. Sendo assim, é de grande valia fazer-se a análise comportamental da rodovia, por meio de avaliações funcionais e estruturais a fim de que se adote prática de soluções de restauração eficientes.

Dessa forma, ao visar uma análise comportamental mais detalhada e precisa, foram compilados dados referentes às condições estruturais e funcionais com o objetivo de subdividi-los em segmentos 
homogêneos. A correta avaliação de um segmento homogêneo carece de diversos critérios e variáveis muito bem definidas, além de uma base de dados consistente. De forma geral, a escolha da variável se baseou no contexto de avaliação estrutural e funcional, portanto, teve como parâmetro estrutural a espessura do concreto asfáltico e deflexão, afundamento de trilha de roda, irregularidade longitudinal e trincamento como parâmetros funcionais, o que possibilitou a identificação de uma quantidade significativa de novos segmentos com características similares.

Para compilação dos resultados em uma matriz única foi adotado o método de hierarquização, considerando, em ordem geomorfologia, deflexão, trincamento, afundamento de trilha de roda, irregularidade longitudinal e espessura da camada de revestimento asfáltico. Foi possível a identificação de 45 segmentos homogêneos ao longo dos 20 quilômetros do trecho analisado. Sendo o intervalo mínimo igual a 300 metros e máximo de 1.100 metros. Ao comparar com a divisão realizada em 2015 pela empresa responsável pela administração da rodovia, percebe-se que houve um aumento significativo na quantidade de segmentos homogêneos identificados.

Após análise das possíveis causas que resultaram no acréscimo da quantidade de segmentos homogêneos, evidenciam-se as alterações - já esperadas - em relação ao tráfego de veículos comerciais da região, assim como, intervenções realizadas na rodovia, totalizando 95 obras de revitalização. Contudo, no que diz respeito avaliação comportamental da rodovia, a nova delimitação dos segmentos homogêneos permitirá um número maior de dados para analisar, proporcionando então, uma avaliação mais minuciosa.

\section{REFERÊNCIAS}

AASHTO. American Association of State Highway and Tranportation Officials. Guide for design of pavement structure. Washington, 1993.

BENEVIDES, S. A. S. E.. Modelos de Desempenho de Pavimentos Asfálticos para um Sistema de Gestão de Rodovias Estaduais do Ceará. Tese (Doutorado em Engenharia Civil) - Universidade Federal do Rio de Janeiro, Rio de Janeiro, 2006.

BERNUCCI, L. B.; CERATTI, J. A. P.; MOTTA, L. M. G.; SOARES, J. B.. Pavimentação asfáltica: formação básica para engenheiros. 3 ed. Rio de Janeiro: PETROBRAS, 2008.

CNT. Confederação Nacional do Transporte. Boletim Estatístico - CNT. 2018.

DER-SP. IP-DE-P00/003: Avaliação funcional e estrutural de pavimento. Instrução de Projeto. São Paulo, 2006.

DNIT. Instituto de Pesquisas Rodoviárias. IPR-720: Manual de Restauração de Pavimentos Asfálticos. Rio de Janeiro: Ministério dos Transportes, 2006.

DNIT. Instituto de Pesquisas Rodoviárias. IPR-745: Manual de Gerência de Pavimentos. Rio de Janeiro: Ministério dos Transportes, 2011.
DNER. Departamento Nacional de Infraestrutura de Transportes. PRO-10/79: Avaliação Estrutural dos Pavimentos Flexíveis. Rio de Janeiro, 1979a.

HUDSON, W. R.; HAAS, R.;UDDIN, W.. Infrastructure Management. New York: McGraw-Hill Companies, 1997.

LIMA, O. F.. Desempenho em serviços de transportes: conceitos, métodos e práticas. Tese (Doutorado em Livre Docência) - Universidade Estadual de Campinas. Campinas. 2004.

MARRA, C.. Caracterização da demanda de movimentações urbanas de cargas. Dissertação (Mestrado em Engenharia Civil) - Universidade Estadual de Campinas, Campinas, 1999.

MARTINS, C. A.; ARANTES, R. C. C.; SILVA. B. A.; ROMEIRO JUNIOR, C. L. S.. Desenvolvimento de Modelos de Desempenho de Pavimentos Asfálticos para a Rodovia BR040. In: REUNIÃO DE PAVIMENTAÇÃO URBANA, 20. Anais. Florianópolis, 2017.

MELLO, J. C.. Planejamento de Transportes. São Paulo: McGraw-Hill, 1975.

RODRIGUES, R. M.. Gerência de pavimentos - parte II: Apostila da Disciplina de Gerência de Pavimentos. São Carlos: Instituto Tecnológico de Aeronáutica - ITA, 2003. 
VIEIRA, S. A.; PINHO JÚNIOR, A. A. E.; OLIVEIRA, F. H. L.;

AGUIAR, M. F. P.. Análise Comparativa de Metodologias de Avaliação de Pavimentos através do IGG e PCl. Conex. Ci. E Tecnol. Fortaleza, v.10, n.3, p.20-30, 2016.
VISCONTI, T. S.. O Sistema de Gerencial de Pavimentos.

Departamento Nacional de Estradas de Rodagem, Instituto de Pesquisas Rodoviárias, 2000.

A CBPC - Companhia Brasileira de Produção Científica (CNPJ: 11.221.422/0001-03) detém os direitos materiais desta publicação. Os direitos referem-se à publicação do trabalho em qualquer parte do mundo, incluindo os direitos às renovações, expansões e disseminações da contribuição, bem como outros direitos subsidiários. Todos os trabalhos publicados eletronicamente poderão posteriormente ser publicados em coletâneas impressas sob coordenação da Sustenere Publishing, da Companhia Brasileira de Produção Científica e seus parceiros autorizados. Os (as) autores (as) preservam os direitos autorais, mas não têm permissão para a publicação da contribuição em outro meio, impresso ou digital, em português ou em tradução. 